\title{
Assessing Neurofilaments as Biomarkers of Neuroprotection in Progressive Multiple Sclerosis
}

\author{
From the MS-STAT Randomized Controlled Trial
}

Thomas E. Williams, BA, MB BChir, MRCP, Katherine P. Holdsworth, MSc, Jennifer M. Nicholas, PhD, Arman Eshaghi, PhD, Theodora Katsanouli, MSc, Henrietta Wellington, PhD, FRCP, Amanda Heslegrave, PhD, Henrik Zetterberg, PhD, Chris Frost, PhD, and Jeremy Chataway, PhD, FRCP

Neurol Neuroimmunol Neuroinflamm 2022;9:e1130. doi:10.1212/NXI.0000000000001130

\section{Abstract}

\section{Background and Objectives}

Improved biomarkers of neuroprotective treatment are needed in progressive multiple sclerosis (PMS) to facilitate more efficient phase 2 trial design. The MS-STAT randomized controlled trial supported the neuroprotective potential of high-dose simvastatin in secondary progressive MS (SPMS). Here, we analyze serum from the MS-STAT trial to assess the extent to which neurofilament light (NfL) and neurofilament heavy ( $\mathrm{NfH}$ ), both promising biomarkers of neuroaxonal injury, may act as biomarkers of simvastatin treatment in SPMS.

\section{Methods}

The MS-STAT trial randomized patients to $80 \mathrm{mg}$ simvastatin or placebo. Serum was analyzed for NfL and NfH using Simoa technology. We used linear mixed models to investigate the treatment effects of simvastatin compared with placebo on $\mathrm{NfL}$ and $\mathrm{NfH}$. Additional models examined the relationships between neurofilaments and MRI and clinical measures of disease severity.

\section{Results}

A total of 140 patients with SPMS were included. There was no evidence for a simvastatin treatment effect on $\mathrm{NfL}$ or $\mathrm{NfH}$ : compared with placebo, NfL was $1.2 \%$ lower (95\% CI 10.6\% lower to $9.2 \%$ higher; $p=0.820$ ) and $\mathrm{NfH}$ was $0.4 \%$ lower (95\% CI $18.4 \%$ lower to $21.6 \%$ higher; $p=0.969$ ) in the simvastatin treatment group. Secondary analyses suggested that higher NfL was associated with greater subsequent whole brain atrophy, higher T2 lesion volume, and more new/enlarging T2 lesions in the previous 12 months, as well as greater physical disability. There were no significant associations between $\mathrm{NfH}$ and MRI or clinical variables.

\section{Discussion}

We found no evidence of a simvastatin treatment effect on serum neurofilaments. While confirmation of the neuroprotective benefits of simvastatin is awaited from the ongoing phase 3 study (NCT03387670), our results suggest that treatments capable of slowing the rate of whole brain atrophy in SPMS, such as simvastatin, may act via mechanisms largely independent of neuroaxonal injury, as quantified by NfL. This has important implications for the design of future phase 2 clinical trials in PMS.

\section{Trial Registration Information}

MS-STAT: NCT00647348.

\author{
Correspondence \\ Dr. Williams \\ thomas.e.williams@ucl.ac.uk
}

\section{Class of Evidence}

MORE ONLINE

Criteria for rating

therapeutic and diagnostic studies

NPub.org/coe 


\section{Glossary}

9HPT $=$ 9-hole peg test $; 25 \mathrm{FW}=25$-foot timed walk; $\mathrm{CoV}=$ coefficient of variation; EDSS = Expanded Disability Status Scale; $\mathbf{I Q R}=$ interquartile range; $\mathbf{L L o Q}=$ lower limit of quantification; $\mathbf{M S}=$ multiple sclerosis; $\mathbf{N f H}=$ neurofilament heavy; $\mathbf{N f L}=$ neurofilament light; PMS = progressive MS; SPMS = secondary progressive MS; T2LV = T2 lesion volume.

\section{Classification of Evidence}

This study provides class I evidence that simvastatin treatment does not have a large impact on either serum NfL or NfH, as quantified in this study, in SPMS.

Few treatments are available for progressive multiple sclerosis (PMS), with most restricted to those with active inflammatory disease. Treatments for nonactive $\mathrm{PMS}^{1}$ may require an alternative approach, utilizing neuroprotective mechanisms alone or in combination with immunomodulation. One such candidate neuroprotective treatment is simvastatin, which in the MSSTAT trial demonstrated a $43 \%$ reduction in annualized brain atrophy, in addition to benefits on secondary physical and cognitive outcomes. No differences were noted on a panel of immunologic markers, supporting a neuroprotective rather than immunomodulatory mechanism., ${ }^{2,3}$ The phase 3 MS-STAT2 study is ongoing (NCT03387670).

Blood neurofilament light (NfL) is a biomarker of neuroaxonal injury and an appealing surrogate outcome measure for trials in relapsing-remitting MS. ${ }^{4}$ It is less well studied in PMS. ${ }^{5}$ Initiation of immunosuppressive disease-modifying treatment is associated with a reduction in blood NfL in PMS cohorts, but an important question remains over the ability of NfL to capture the treatment effect of purportedly neuroprotective therapies. ${ }^{6-9}$ Clarifying this is an important goal of the progressive MS alliance, with implications on future phase 2 trial design. ${ }^{10}$ Data for blood neurofilament heavy $(\mathrm{NfH})$ are more limited, but it may have utility as a biomarker of neuroprotection. ${ }^{11,12}$

Here, we analyze serum NfL and NfH from the MS-STAT trial. We use the known positive effect of simvastatin on whole brain atrophy to interrogate our primary research question: whether serum $\mathrm{NfL}$ and $\mathrm{NfH}$ may act as biomarkers of neuroprotective treatment with simvastatin in secondary progressive MS (SPMS). We additionally perform further analyses to examine the relationships between serum neurofilaments and established MRI and clinical variables.

\section{Methods}

\section{MS-STAT Trial and Sample Processing}

The MS-STAT study protocol has been outlined previously. ${ }^{2}$ Briefly, patients with SPMS, aged 18-65 years with Expanded Disability Status Scale (EDSS) score 4.0-6.5, were eligible. Key exclusion criteria included primary progressive MS; relapse or steroid use within 3 months; and the use of immunosuppressive or disease-modifying therapy within the last 6 months. A total of
140 patients were randomized, $1: 1$, to simvastatin $80 \mathrm{mg}$ or placebo. Baseline characteristics are shown in Table 1. Blood samples were acquired at baseline and months 6,12 , and 24 . Serum was separated and stored at $-80^{\circ} \mathrm{C}$ until time of analysis.

\section{Neurofilament Quantification}

$\mathrm{NfL}$ and $\mathrm{NfH}$ are components of a neurone-specific intermediate filament, differing in their C-terminal domain and phosphorylation state. Both are released following neuroaxonal injury into the CSF and blood, where they may be quantified. Serum NfL and NfH were measured by Simoa technology on a HD-1 analyzer, according to the manufacturer's instructions (Quanterix, Billerica, MA). The Simoa NF-Light Advantage and Simoa pNF-heavy Discovery Kits (Quanterix) were used. Briefly, serum samples were thawed at $21^{\circ} \mathrm{C}$, vortexed, and centrifuged at 10,000 RCF for 5 minutes at $21^{\circ} \mathrm{C}$. On-board the HD-1, samples were diluted $1: 4$ with sample diluent and bound to paramagnetic beads coated with a capture antibody specific for human NfL or NfH. Antibodycoated beads were incubated with a biotinylated anti-NfL or anti-NfH detection antibodies, that in turn were labeled with a streptavidin- $\beta$-galactosidase complex. Following the addition of the $\beta$-galactosidase substrate resorufin $\beta$-D-galactopyranoside, a fluorescent signal proportional to the concentration of neurofilament present in the sample was generated in the antigen-containing microwells of the Simoa plates.

Duplicate measurements were taken of each sample. Sample concentrations were extrapolated from a standard curve, fitted using a 4-parameter logistic algorithm. The lower limit of quantification (LLoQ) for NfL is $0.174 \mathrm{pg} / \mathrm{mL}$ and for $\mathrm{NfH}$ is $2.88 \mathrm{pg} / \mathrm{mL}{ }^{13,14}$ Values below the LLoQ were assigned the value of half the LLoQ. The coefficient of variation $(\mathrm{CoV})$ between sample replicates tends to be higher for lower value results. To avoid bias, all data were therefore included in the primary statistical analysis regardless of the $\mathrm{CoV}$. Each assay was run in the same or consecutive batches by the same operator, who was blinded to treatment allocation.

\section{MRI Processing}

The imaging data have been previously published and were acquired as previously described. ${ }^{2,15}$ Briefly, 3D T1-weighted, double-echo proton density, and T2-weighted MRI was obtained at baseline, month 12 , and month 25 . Whole brain 
Table 1 Characteristics of the MS-STAT Trial Cohort and Descriptive Statistics for Serum NfL and Serum NfH Across Time Points

\begin{tabular}{|c|c|c|c|}
\hline & Placebo $(n=70)$ & Simvastatin $(n=70)$ & All $(N=140)$ \\
\hline \multicolumn{4}{|l|}{ Baseline characteristics } \\
\hline Sex, $n(\%)$, female & $48(69)$ & $49(70)$ & $97(69)$ \\
\hline Ethnicity, n (\%), White & $63(90)$ & $69(99)$ & $132(94)$ \\
\hline Relapse in last 24 mo, n (\%) & $18(26)$ & $8(11)$ & $26(19)$ \\
\hline Age, y, mean (SD) & $51.1(6.8)$ & $51.5(7.0)$ & $51.3(6.9)$ \\
\hline MS duration, $y$, mean (SD) & $20.3(8.8)$ & $22.1(8.3)$ & $21.2(8.6)$ \\
\hline SPMS duration, y, mean (SD) & $7.1(4.8)$ & $7.3(5.6)$ & $7.2(5.2)$ \\
\hline EDSS score, median (IQR) & $6(5.5-6.5)$ & $6(5.5-6.5)$ & $6(5.5-6.5)$ \\
\hline Previous use of interferon, $n(\%)$ & $12(17)$ & $10(14)$ & $22(16)$ \\
\hline \multicolumn{4}{|l|}{ Serum NfL, pg/mL } \\
\hline Baseline, median (IQR) & $15.3(10.2-22.2)$ & $13.9(10.9-19.7)$ & $14.6(10.8-20.2)$ \\
\hline $\mathbf{N}$ & 63 & 65 & 128 \\
\hline Month 6, median (IQR) & $14.8(12.0-23.0)$ & $15.0(11.5-21.8)$ & $14.8(11.7-22.6)$ \\
\hline $\mathbf{N}$ & 53 & 59 & 112 \\
\hline Month 12, median (IQR) & $16.6(12.1-22.3)$ & $16.8(13.3-23.1)$ & $16.7(12.8-22.9)$ \\
\hline $\mathbf{N}$ & 53 & 59 & 112 \\
\hline Month 24, median (IQR) & $16.9(12.4-22.6)$ & $16.0(11.7-21.4)$ & $16.0(11.9-22.2)$ \\
\hline $\mathbf{N}$ & 48 & 64 & 112 \\
\hline \multicolumn{4}{|l|}{ Serum NfH, pg/mL } \\
\hline Baseline, median (IQR) & $64.2(24.0-136.0)$ & $67.4(23.9-116.0)$ & $65.5(24.0-118.5$ \\
\hline $\mathbf{N}$ & 63 & 62 & 125 \\
\hline Month 6, median (IQR) & $71.4(25.7-135.4)$ & $58.0(22.7-112.1)$ & $62.5(22.7-121.9$ \\
\hline $\mathbf{N}$ & 49 & 53 & 102 \\
\hline Month 12, median (IQR) & $66.5(22.9-135.5)$ & $67.2(25.2-107.1)$ & $67.0(25.2-113.6$ \\
\hline $\mathbf{N}$ & 52 & 57 & 109 \\
\hline Month 24, median (IQR) & $71.9(26.6-111.8)$ & $60.0(27.0-125.6)$ & $69.7(27.0-119.5$ \\
\hline $\mathbf{N}$ & 48 & 64 & 112 \\
\hline
\end{tabular}

Abbreviations: EDSS = Expanded Disability Status Scale; IQR = interquartile range; MS = multiple sclerosis; $\mathrm{NfH}=$ neurofilament heavy; $\mathrm{NfL}=$ neurofilament light; SPMS = secondary progressive MS.

atrophy was determined using the boundary shift integral method and expressed as percentage change in whole brain volume. T2 new/enlarging lesions were expressed as a count and $\mathrm{T} 2$ lesion volume (T2LV) in milliliters.

\section{Statistical Analysis}

The prespecified primary analysis was to examine the effect of simvastatin $(80 \mathrm{mg})$ vs placebo on levels of serum $\mathrm{NfL}$ at 24 months. The primary analysis was conducted on the intention to treat population regardless of treatment adherence. An exploratory analysis was undertaken to examine the treatment effect using a per-protocol data set, which included patients who complied with treatment and completed follow-up to 25 months. Participants were considered compliant with treatment if they reported taking, on average, at least $90 \%$ of their tablets at the protocol dose of 2 tablets per day.

The prespecified secondary analysis examined the relationship between serum NfL and whole brain atrophy rate. Further analyses of the association of NfL with other MRI and clinical variables and all analyses of $\mathrm{NfH}$ data were exploratory. Neurofilament data were skewed, and hence, all analyses were 
Table 2 Effect of High-Dose Simvastatin on Serum NfL and Serum NfH

\begin{tabular}{llll}
\hline & $\begin{array}{l}\text { Difference in } \\
\text { geometric mean (\%) }\end{array}$ & $\mathbf{9 5 \%} \mathrm{Cl}$ & $\boldsymbol{p}$ Value \\
\hline Serum NfL (pg/mL) & & & \\
\hline Month 6 & -3.29 & -16.2 to 11.6 & 0.646 \\
\hline Month 12 & 5.35 & -7.4 to 19.9 & 0.429 \\
\hline Month 24 & -5.21 & -17.4 to 8.8 & 0.448 \\
\hline $\begin{array}{l}\text { Mean treatment } \\
\text { effect }\end{array}$ & -1.16 & -10.6 to 9.2 & 0.820 \\
\hline $\begin{array}{l}\text { Serum NfH (pg/mL) } \\
\text { Month 6 }\end{array}$ & -7.22 & -27.9 to 19.4 & 0.560 \\
\hline Month 12 & 4.74 & -15.1 to 29.3 & 0.666 \\
\hline Month 24 & 1.69 & -18.4 to 26.7 & 0.881 \\
\hline $\begin{array}{l}\text { Mean treatment } \\
\text { effect }\end{array}$ & -0.39 & -18.4 to 21.6 & 0.969 \\
\hline
\end{tabular}

Abbreviations: EDSS = Expanded Disability Status Scale; IQR = interquartile range; $\mathrm{NfH}=$ neurofilament heavy; $\mathrm{NfL}=$ neurofilament light.

a Percentage difference in geometric mean serum neurofilaments, simvastatin vs placebo, adjusted for age, sex, dichotomized EDSS scores (4.0-5.5, 6.0-6.5) and study site. Differences are shown for each follow-up visit and also the average treatment effect across all follow-up visits.

performed following $\log _{2}$ transformation. Clinical data included EDSS scores, 25 -foot timed walk (25FW) expressed as speed (inverse of completion time in seconds), and 9-hole peg test $(9 \mathrm{HPT})$ expressed as a speed $(1,000 \times$ inverse of completion time in seconds). Analyses were conducted in Stata 15.1 or later.

\section{Analysis of Simvastatin Treatment Effect on $\mathrm{NfL}$ and $\mathrm{NfH}$}

A mixed effect model was used to estimate the simvastatin treatment effect on serum neurofilaments at 6,12 , and 24 months, for NfL and $\mathrm{NfH}$. A single model was used to estimate a separate treatment effect at each visit $(6,12$, and 24 months) by including a categorical variable for visit and an interaction between visit and treatment group. Baseline neurofilament data were included as an additional end point, but with the treatment effect here constrained to be 0 . This is essentially equivalent to adjusting for the baseline neurofilament level. ${ }^{16}$ The model included an unstructured residual covariance matrix for the residuals (hence allowing a different variance at each visit and different covariances between each pair of measurements on the same participant). The following baseline variables, which were used as minimization factors in the randomization, were adjusted for by including them and their interactions with visit as fixed effects: age, sex, dichotomized EDSS scores (4.0-5.5, 6.0-6.5), and study site. The mean of the estimated treatment effects across all followup visits is also presented. In addition, an exploratory analysis was conducted which adjusted for the minimization factors in the randomization and the following baseline variables: T2LV and number of relapses in the previous 24 months. In these models, we did not perform adjustments for covariates measured after randomization as they may be influenced by the treatment allocation and hence introduce bias into the analysis of treatment effect. ${ }^{17}$

\section{Analysis Relating NfL and NfH to MRI and Clinical Variables}

This analysis used data on baseline neurofilament levels and the rates of change in neurofilament levels during the trial as predictors of MRI and clinical outcomes. A 2-stage analysis was performed.

In the first stage, a summary measure for rate of change in $\mathrm{NfL}$ and $\mathrm{NfH}$ for each participant was calculated as the slope from a simple linear regression model relating each participant's repeated measures of $\log \mathrm{NfL}$, and separately $\log \mathrm{NfH}$, to time from baseline using ordinary least squares. ${ }^{18}$ In the second stage, each participant's estimated rate of change in log NfL or $\log \mathrm{NfH}$ was used as a predictor variable, along with baselinecentered $\log \mathrm{NfL}$ or $\log \mathrm{NfH}$, in a series of separate models for MRI and clinical outcomes. For each outcome, a separate model was fitted for log NfL and $\log \mathrm{NfH}$.

The model for whole brain atrophy was an extension of a previously described linear mixed model for directly measured change between each pair of MRI visits (baseline to 12, baseline to 25 , and $12-25$ months) as the outcome. ${ }^{19}$ It included participant-level random slopes for time between scans and random effects for visit. All predictor variables were included as interactions with time between scans in order to model the associations with atrophy rate. The model included baseline neurofilaments and change in neurofilaments, as well as the following baseline variables: age, sex, MRI site, SPMS duration, relapse in the previous 24 months, previous use of interferon, and baseline treatments for fatigue, depression, neuropathic pain, spasticity, and bladder urgency.

The model for T2LV was a linear mixed model with T2LV at each MRI visit (baseline, 12 months, and 25 months) as the outcome. Analysis of 25FW and 9HPT used a linear mixed model with speed at each visit (baseline, 12 months, and 24 months) as the outcome. These models included participant level random slopes for change over time and random intercepts, allowing for correlation between these random effects. In each model, baseline log neurofilament was included as a predictor, along with its interaction with time since baseline. Analysis of T2LV additionally included change in log neurofilament and its interaction with time. The models for T2LV included the same variables that were adjusted for in the whole brain atrophy model on their own as well as an interaction with time. The models for clinical variables included these same adjustments, with the exception of MRI site. As T2LV and clinical variables violated normality assumptions, inference from these models is based on nonparametric biascorrected and accelerated $95 \%$ and $99 \%$ CIs calculated from 10,000 bootstrap replications clustered on participant. $p$ 

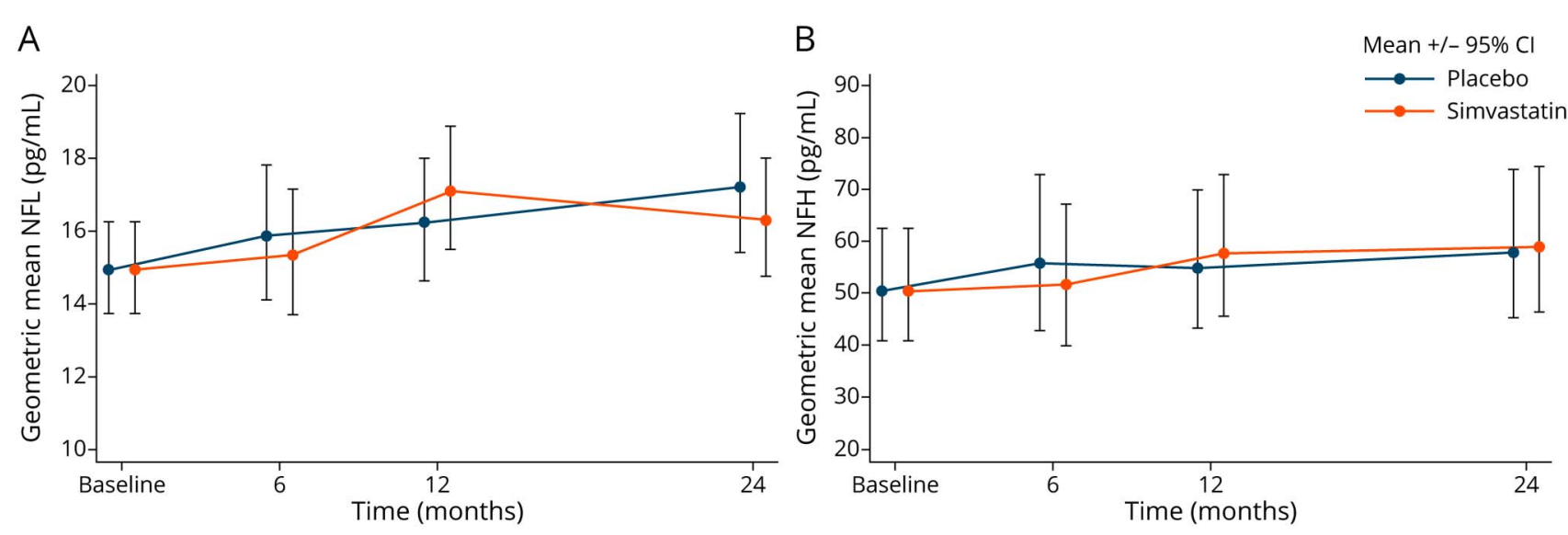

Values are marginal adjusted geometric means from linear mixed models with treatment effect at baseline constrained to 0 . There was no evidence for a treatment effect on either $\mathrm{NfL}$ or $\mathrm{NfH}$. $\mathrm{NfH}=$ neurofilament heavy; $\mathrm{NfL}$ = neurofilament light.

values are therefore not calculated for these models, but the ranges in which they lie can be inferred from the CIs.

For the EDSS score, the linear mixed model did not converge. Instead, a linear regression model for score at each visit (baseline, 12 months, and 24 months) was used. To allow for the nonindependence of measures from the same participant, nonparametric bias-corrected and accelerated CIs clustered on participant were used as described above. The models for the EDSS score included the same adjustment variables as for the other clinical outcomes.

Although T2LV may reflect overall disease burden, the identification of active lesions (either gadolinium-enhancing lesions on a single scan or new/enlarging T2 lesions when comparing 2 time points) is the key MRI measure of ongoing neuroinflammation. ${ }^{20}$ The MS-STAT cohort did not include gadolinium-enhanced imaging, and new/enlarging T2 lesions cannot be determined at baseline. To further explore the known relationship between serum NfL and neuroinflammation in this SPMS cohort, we therefore performed additional exploratory linear regression modeling using month $24 \log \mathrm{NfL}$ as the dependent variable. This allowed inclusion of recent active lesions (new/enlarging T2 lesions during month 0 to month 12 and month 12 to month 25) and concurrent T2LV (month 25) as predictors. Models were fitted including each of the MRI variables on their own and then together in a mutually adjusted multivariable model. These models included the same covariates as the T2LV models.

\section{Standard Protocol Approvals, Registrations, and Patient Consents}

The study was conducted in accordance with Good Clinical Practice and the Declaration of Helsinki. ${ }^{21}$ The MS-STAT protocol was approved by each study site's institutional review board and a national ethics committee; all patients gave written informed consent before entering the study; and ethical approval for the retrospective analysis of serum samples was received. The MS-STAT clinical trial identification number is NCT00647348.

\section{Data Availability}

Anonymized NfL and $\mathrm{NfH}$ data are provided as a supplementary data file (links.lww.com/NXI/A679).

\section{Results}

\section{NfL and NfH Data}

Data on NfL were available from at least 1 visit for 138 patients (69 in each treatment group), with 128 patients having $\mathrm{NfL}$ data from at least 1 follow-up visit (61 placebo; 67 simvastatin). For $\mathrm{NfH}$, data were available from 137 patients (69 placebo; 68 simvastatin), with 127 patients having $\mathrm{NfH}$ data from at least 1 follow-up visit (60 placebo; 67 simvastatin). No $\mathrm{NfL}$ measures were below the LLoQ, and all sample replicates had a $\mathrm{CoV}<20 \%$. For $\mathrm{NfH}, 8$ samples $(1.8 \%)$ were below the LLoQ and 39 samples $(8.6 \%)$ had a $\mathrm{CoV}>20 \%$. At baseline, median NfL was $14.6 \mathrm{pg} / \mathrm{mL}$ (interquartile range [IQR] $10.8-20.2 \mathrm{pg} / \mathrm{mL}$ ), and median $\mathrm{NfH}$ was $65.5 \mathrm{pg} / \mathrm{mL}$ (IQR $24.0-118.5 \mathrm{pg} / \mathrm{mL}$ ) (Table 1). Characteristics of the perprotocol dataset are included in eTable 1 (links.lww.com/ NXI/A679).

\section{Analysis of Simvastatin Treatment Effect on $\mathrm{NfL}$ and $\mathrm{NfH}$}

There was no evidence of a simvastatin treatment effect on either NfL or $\mathrm{NfH}$ at any time point (Table 2), with adjusted marginal mean $\mathrm{NfL}$ and $\mathrm{NfH}$ levels being similar in the 2 treatment groups at each follow-up visit (Figure 1). Taking the mean of the treatment effects across all follow-up time points, the geometric mean NfL was $1.2 \%$ lower in the simvastatin group than in the placebo group (95\% CI $10.6 \%$ lower to $9.2 \%$ higher; $p=0.820$ ), whereas the geometric mean $\mathrm{NfH}$ was $0.4 \%$ lower in the simvastatin group than on placebo 
Table 3 Relationship Between Serum NfL, NfH, and Imaging Variables

\begin{tabular}{|c|c|c|c|}
\hline & Parameter estimate & $95 \% \mathrm{Cl}$ & $p$ Value \\
\hline \multicolumn{4}{|l|}{ Whole brain atrophy } \\
\hline \multicolumn{4}{|c|}{ Relationship with rate of whole brain atrophy (\% per year) } \\
\hline \multicolumn{4}{|l|}{ Predictor variable } \\
\hline Baseline NfL (per doubling) & 0.207 & 0.072 to 0.341 & 0.003 \\
\hline Rate of change in NfL (doublings per year ${ }^{\mathrm{a}}$ ) & 0.093 & -0.201 to 0.387 & 0.535 \\
\hline Baseline NfH (per doubling) & 0.048 & -0.005 to 0.102 & 0.078 \\
\hline Rate of change in $\mathrm{NfH}$ (doublings per year ${ }^{\mathrm{a}}$ ) & 0.016 & -0.105 to 0.136 & 0.795 \\
\hline
\end{tabular}

T2 lesion volume

\begin{tabular}{|c|c|c|c|}
\hline \multicolumn{4}{|l|}{ Relationship with baseline $\mathrm{T} 2$ lesion volume $(\mathrm{mL})$} \\
\hline \multicolumn{4}{|l|}{ Predictor variable } \\
\hline Baseline NfL (per doubling) & 7.68 & 3.66 to 12.48 & $<0.01$ \\
\hline Rate of change in NfL (doublings per year ${ }^{\mathrm{a}}$ ) & 15.08 & 6.67 to 26.40 & $<0.01$ \\
\hline Baseline NfH (per doubling) & 0.736 & -0.921 to 2.631 & $>0.05$ \\
\hline Rate of change in $\mathrm{NfH}$ (doublings per year ${ }^{\mathrm{a}}$ ) & 0.413 & -6.696 to 8.001 & $>0.05$ \\
\hline \multicolumn{4}{|l|}{ Relationship with change in $\mathrm{T} 2$ lesion volume $(\mathrm{mL} / \mathrm{y})$} \\
\hline \multicolumn{4}{|l|}{ Predictor variable } \\
\hline Baseline NfL (per doubling) & 0.29 & -0.14 to 0.63 & $>0.05$ \\
\hline Rate of change in NfL (doublings per year ${ }^{\mathrm{a}}$ ) & 0.39 & -0.60 to 1.02 & $>0.05$ \\
\hline Baseline NfH (per doubling) & -0.070 & -0.218 to 0.051 & $>0.05$ \\
\hline Rate of change in $\mathrm{NfH}$ (doublings per year ${ }^{\mathrm{a}}$ ) & -0.032 & -0.535 to 0.541 & $>0.05$ \\
\hline \multicolumn{4}{|c|}{$\begin{array}{l}\text { Abbreviations: } \mathrm{NfH}=\text { neurofilament heavy; } \mathrm{NfL}=\text { neurofilament light. } \\
\text { The results of } 4 \text { separate models are presented, with whole brain atrophy or } \mathrm{T} 2 \text { lesion volume as the dependent variables and } \mathrm{NfL} \text { or } \mathrm{NfH} \text { data as the predictor } \\
\text { variables. In all analyses, neurofilament data were } \log _{2} \text { transformed. Results are from covariate adjusted models as indicated in the Methods section. For T2 } \\
\text { lesion volume, the } p \text { value bounds ( }<>>0.05 \text { and }<>>0.01 \text { ) can only be inferred from the } 95 \% \text { and } 99 \% \text { bias-corrected and accelerated cluster bootstrap (10,000 } \\
\text { replications) Cls. } \\
\text { A } 1 \text {-unit increase in the number of doublings per year corresponds to a change from stable levels to a doubling per year or from doubling once every year to } \\
\text { doubling every } 6 \text { months ( } 2 \text { doublings per year). }\end{array}$} \\
\hline
\end{tabular}

(95\% CI $18.4 \%$ lower to $21.6 \%$ higher; $p=0.969$ ). The results from the exploratory per-protocol analysis were similar to those found for the intention-to-treat analysis, with no evidence of a simvastatin treatment effect on either $\mathrm{NfL}$ or $\mathrm{NfH}$ at any time point (eTable 2, links.lww.com/NXI/A679).

Sensitivity analyses found that the results were not materially altered following the exclusion of 2 individuals with outlying neurofilament values. In addition, an exploratory analysis found that results were essentially unchanged with adjustment for baseline lesion volume and relapses within the last 24 months (eTable 3, links.lww.com/NXI/A679).

\section{Association of NfL and NfH With MRI Variables}

The relationships between both $\mathrm{NfL}$ and $\mathrm{NfH}$ and each of whole brain atrophy and T2LV are shown in Table 3 and Figure 2. There was evidence for an association between higher baseline $\mathrm{NfL}$ and faster whole brain atrophy rate and between higher baseline NfL and greater T2LV: a twofold increase in baseline NfL was associated with a $0.21 \% /$ year increase in brain atrophy and with a $7.7 \mathrm{~mL}$ higher baseline T2LV. The rate of change in NfL was not associated with the rate of change in T2LV or the rate of brain atrophy. Patients with a greater increase in NfL from baseline to month 24, however, tended to have a higher T2LV at baseline and follow-up time points. As there was little effect of change in $\mathrm{NfL}$ on T2LV, the effect was similar across all visits: an increase of 1 extra doubling per year in NfL was associated with a $15.1 \mathrm{~mL}$ higher baseline T2LV and $15.9 \mathrm{~mL}$ higher month $25 \mathrm{~T} 2 \mathrm{LV}$. There was no evidence for an association between $\mathrm{NfH}$ and any MRI variables (Table 3; Figure 2).

$\mathrm{NfL}$ at month 24 was associated with concurrent T2LV and new/enlarging T2 lesions between baseline and month 12 and between months 12 and 25 when examined in separate models (Table 4). When these were combined together as 
Figure 2 Relationship Between Each of Baseline Serum NfL and NfH and Each of Whole Brain Atrophy Rate and Baseline T2 Lesion Volume

A. Baseline NFL and subsequent whole brain atrophy rate

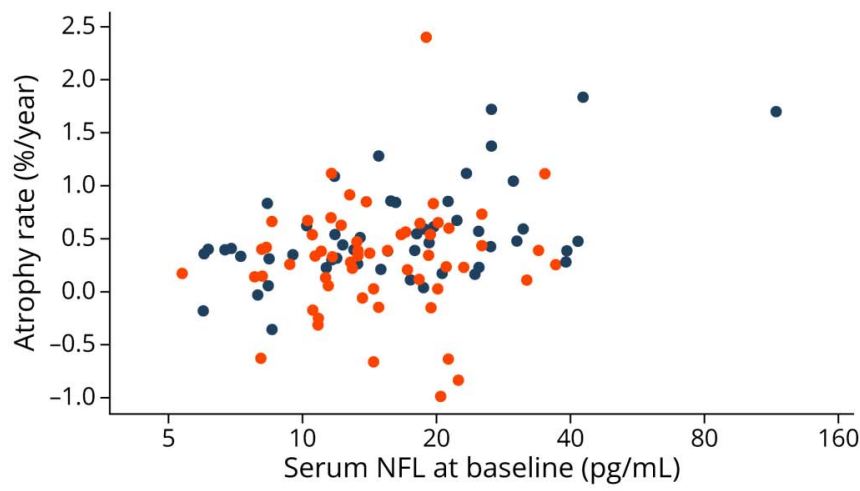

C. Baseline NFL and baseline T2 lesion volume

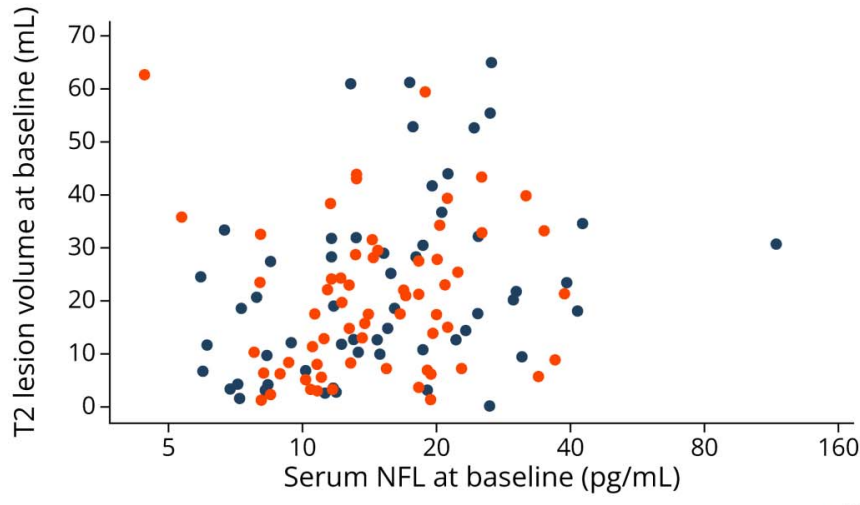

B. Baseline NFH and subsequent whole brain atrophy rate

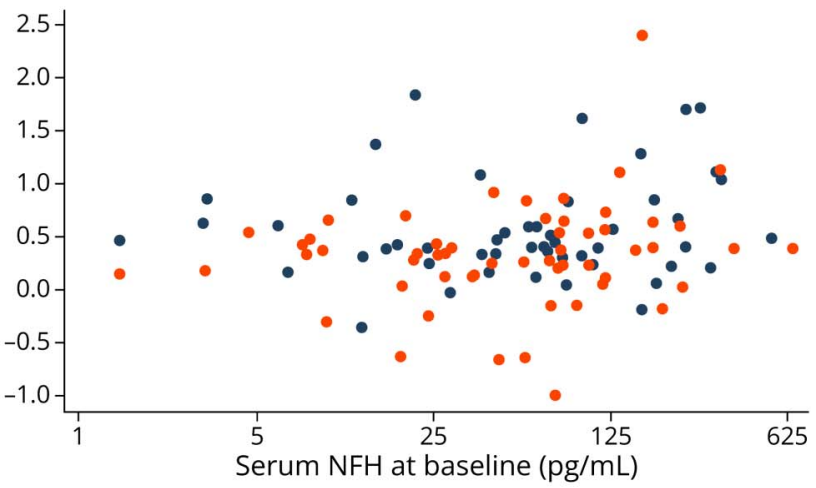

D. Baseline NFH and baseline T2 lesion volume

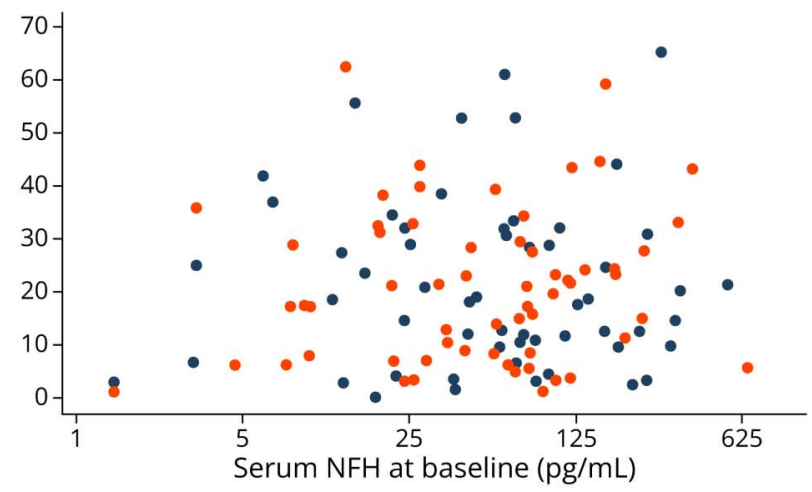

- Placebo

- Simvastatin

Points represent individual patient data. Whole brain atrophy rate is reported as yearly \% change from baseline to month 25 and baseline $T 2$ lesion volume in milliliters. (A) Baseline NfL and baseline to month 25 whole brain atrophy rate. (B) Baseline $\mathrm{NfH}$ and baseline to month 25 whole brain atrophy rate. (C) Baseline NfL and baseline T2 lesion volume. (D) Baseline NfH and baseline T2 lesion volume. $\mathrm{NfH}=$ neurofilament heavy; $\mathrm{NfL}=$ neurofilament light.

predictors in the same mutually adjusted model, both concurrent T2LV and month 12-25 new/enlarging T2 lesions remained independently associated with month $24 \mathrm{NfL}$, whereas the association with new and enlarging lesions between baseline and month 12 was lost. In the final model, month $24 \mathrm{NfL}$ was increased by $5.7 \%$ for each new/enlarging T2 lesion between months 12 and 25 and by $0.89 \%$ for each milliliter increase in month $25 \mathrm{~T} 2 \mathrm{LV}$.

\section{Association of NfL and NfH With Clinical Variables}

Higher baseline NfL was significantly associated with higher baseline EDSS score, but not with the rate of change in the EDSS score from baseline to 2 years (Table 5). Higher baseline NfL was also associated with worse baseline 9HPT performance and with a greater rate of worsening in the $25 \mathrm{FW}$ speed from baseline to 2 years. Baseline $\mathrm{NfH}$ was not materially associated with any clinical variables. Sensitivity analyses demonstrated that the results were not materially changed following the exclusion of 2 neurofilament outliers.

\section{Classification of Evidence}

This study assessed the ability of serum NfL and NfH to act as biomarkers of a neuroprotective treatment response with highdose simvastatin, compared with placebo, in patients with SPMS. It provides Class I evidence that these biomarkers, as quantified in this study, do not act as biomarkers of neuroprotection with simvastatin.

\section{Discussion}

Our results demonstrate that despite simvastatin reducing the annualized whole brain atrophy rate by $43 \%$ per year, compared with placebo, we did not find evidence to support a simvastatin treatment effect on serum $\mathrm{NfL}$ or $\mathrm{NfH}$. We also replicate previously observed findings, demonstrating that higher NfL is associated with a greater subsequent rate of whole brain atrophy and that recent inflammatory activity (new/enlarging T2 lesions), as well as T2LV, is associated with higher NfL.

The existing literature suggests that in MS, the degree of neuroaxonal injury reflected by serum $\mathrm{NfL}$ is predominantly 
Table 4 MRI Predictors of Month 24 Serum NfL

\begin{tabular}{|c|c|c|c|c|c|c|}
\hline \multirow[b]{2}{*}{ Predictor variable } & \multicolumn{3}{|c|}{ Separate model for each T2 lesion variable } & \multicolumn{3}{|c|}{ Combined, mutually adjusted, model } \\
\hline & $\begin{array}{l}\% \text { Increase in } 24 \mathrm{mo} \mathrm{NfL} \mathrm{per} \\
\text { unit increase in predictor }\end{array}$ & $95 \% \mathrm{Cl}$ & $p$ Value & $\begin{array}{l}\% \text { increase in } 24 \text { mo NfL per } \\
\text { unit increase in predictor }\end{array}$ & $95 \% \mathrm{Cl}$ & $p$ Value \\
\hline $\begin{array}{l}\text { Month 0-12 T2 new/ } \\
\text { enlarging lesions (count) }\end{array}$ & 3.23 & 0.29 to 6.26 & 0.031 & -0.15 & -3.08 to 2.86 & 0.919 \\
\hline $\begin{array}{l}\text { Month 12-25 T2 new/ } \\
\text { enlarging lesions (count) }\end{array}$ & 6.76 & 3.45 to 10.18 & $<0.001$ & 5.73 & 2.40 to 9.17 & 0.001 \\
\hline $\begin{array}{l}\text { Month } 25 \mathrm{~T} 2 \text { lesion } \\
\text { volume }(\mathrm{mL})\end{array}$ & 1.10 & 0.51 to 1.67 & $<0.001$ & 0.89 & 0.29 to 1.49 & 0.004 \\
\hline
\end{tabular}

Abbreviation: $\mathrm{NfL}=$ neurofilament light.

Results are presented from the 3 separate models, and then from the combined linear regression model, with month $24 \mathrm{NfL}$ out the outcome and T2 lesion variables as predictors. Results are from covariate adjusted models as indicated in the Methods section. As previously, NfL was log 2 transformed. T2 new/ enlarging lesions are reported as a count and T2 lesion volume in milliliters. Coefficients are expressed as \% increase in 24 month NfL per unit increase in T2 lesion variables.

related to ongoing neuroinflammation. Such neuroinflammation may be detected by conventional MRI measures, such as recent T1 gadolinium-enhancing lesions or new T2 lesions, or by advanced MRI measures of chronic neuroinflammation, such as the identification of chronic active lesions via their paramagnetic rims. ${ }^{5,22}$ Our previous findings suggested that simvastatin treatment was not systemically immunomodulating in this cohort, hence providing 1 possible rational for the absence of a treatment effect on NfL. ${ }^{2}$

Many of the pathophysiologic mechanisms contributing to progressive MS ultimately converge on neuroaxonal damage, which may be reflected by increased NfL. ${ }^{23}$ The dissociation between the previously observed benefits of simvastatin (on whole brain atrophy and disability measures) and the absence of a treatment effect on NfL, however, does also highlight the potential importance of additional processes, independent of neuroaxonal injury, in the pathophysiology of SPMS. Comorbidities, particularly cardiovascular, are prevalent within the MS population and are known to have an impact on future disability and brain atrophy. ${ }^{2426}$ MRI measures of brain atrophy have been validated against clinical treatment effects, long-term disability outcomes, and measures of neuroaxonal loss. ${ }^{27-30}$ Brain atrophy is, however, not specific to neuroaxonal injury and may be influenced by volume changes in other CNS tissue compartments. The mechanism of action of simvastatin in progressive MS is the subject of an ongoing mechanistic vascular perfusion study (OPT-MS, NCT03896217), and the ultimate confirmation of the efficacy of simvastatin in SPMS awaits the results of the ongoing phase 3 MS-STAT2 trial (NCT03387670). Our data therefore suggest that caution is required when considering NfL as an outcome measure for treatments in progressive MS if the mechanism of action is not known to directly affect neuroaxonal injury, such as with simvastatin.

Although our results are not necessarily generalizable to other neuroprotective treatments in PMS, they are supported by data from ibudilast. The SPRINT-MS study demonstrated a significant $48 \%$ reduction in the rate of brain atrophy in PMS with ibudilast compared with placebo. ${ }^{31}$ There was, however, no significant difference between the treatment groups in either serum or CSF NfL. ${ }^{9}$ Although ibudilast is likely to have pleotropic effects (such as modulation of CNS innate immunity through inhibition of phosphodiesterases, macrophage migration inhibitory factor, and Toll-like receptor 4), like simvastatin, it is not thought to be systemically immunomodulatory. ${ }^{32}$

NfL has shown utility as a biomarker of treatment with fingolimod, siponimod, natalizumab, and ocrelizumab in PMS cohorts. ${ }^{6-8}$ These treatments all share a predominantly immunomodulatory mechanism of action, and their ability to reduce $\mathrm{NfL}$ is therefore entirely in keeping with the known association between NfL, neuroaxonal injury, and markers of inflammatory activity in PMS. ${ }^{5}$ Supporting this, subgroup analyses suggest that there may be a greater treatment effect of natalizumab, siponimod, and ocrelizumab on $\mathrm{NfL}$ in patients with recent inflammatory activity. ${ }^{6-8}$

The estimated treatment effects of simvastatin on $\mathrm{NfL}$ and $\mathrm{NfH}$ were small and not statistically significant, with the 95\% CI sufficiently narrow to exclude an important treatment effect in either direction. Exploratory analyses did find that the month 24 serum NfL level increased by $6 \%$ (95\% CI $2 \%$ to $9 \%$ ) for each new/enlarging $\mathrm{T} 2$ lesion in the preceding year and by $0.9 \%$ (95\% CI $0.3 \%$ to $1.5 \%$ ) for each milliliter increase in concurrent $\mathrm{T} 2 \mathrm{LV}$, further supporting the known relationship between NfL and neuroinflammation. The key question of this study, however, was to determine the extent to which serum neurofilaments may act as biomarkers of a neuroprotective treatment that does not appear to have direct effects on neuroinflammation, using simvastatin as our example. Indeed, $\mathrm{NfL}$ has shown utility as a biomarker of noninflammatory neurodegeneration and neuroprotection in other neurologic conditions. ${ }^{33,34}$ Our results, however, together with those from SPRINT-MS, suggest that either these treatments produce benefits on the rate of whole brain atrophy by mechanisms independent of neuroaxonal injury or that the degree of neuroprotection induced is insufficient to produce material 
Table 5 Relationship Between Baseline Serum NfL and Serum NfH and Clinical Variables

\begin{tabular}{|c|c|c|c|}
\hline & Parameter estimate & $95 \% \mathrm{Cl}$ & $p$ Value \\
\hline \multicolumn{4}{|l|}{ EDSS score } \\
\hline \multicolumn{4}{|c|}{ Relationship with baseline EDSS score } \\
\hline \multicolumn{4}{|l|}{ Predictor variable } \\
\hline Baseline NfL (per doubling) & 0.284 & 0.096 to 0.500 & $<0.01$ \\
\hline Baseline NfH (per doubling) & -0.030 & -0.109 to 0.058 & $>0.05$ \\
\hline \multicolumn{4}{|c|}{ Relationship with change in the EDSS score (units per year) } \\
\hline \multicolumn{4}{|l|}{ Predictor variable } \\
\hline Baseline NfL (per doubling) & 0.026 & -0.052 to 0.112 & $>0.05$ \\
\hline Baseline NfH (per doubling) & 0.002 & -0.030 to 0.036 & $>0.05$ \\
\hline \multicolumn{4}{|l|}{ 25FW } \\
\hline \multicolumn{4}{|c|}{ Relationship with baseline $25 \mathrm{FW}(1 / \mathrm{s})$} \\
\hline \multicolumn{4}{|l|}{ Predictor variable } \\
\hline Baseline NfL (per doubling) & -0.159 & -0.390 to 0.056 & $>0.05$ \\
\hline Baseline NfH (per doubling) & 0.055 & -0.044 to 0.147 & $>0.05$ \\
\hline \multicolumn{4}{|c|}{ Relationship with change in $25 \mathrm{FW}$ (1/s per year) } \\
\hline \multicolumn{4}{|l|}{ Predictor variable } \\
\hline Baseline NfL (per doubling) & -0.183 & -0.312 to -0.055 & $<0.01$ \\
\hline Baseline NfH (per doubling) & 0.028 & -0.041 to 0.081 & $>0.05$ \\
\hline \multicolumn{4}{|l|}{ 9HPT } \\
\hline \multicolumn{4}{|c|}{ Relationship with baseline 9HPT (1,000/s) } \\
\hline \multicolumn{4}{|l|}{ Predictor variable } \\
\hline Baseline NfL (per doubling) & -3.600 & -5.488 to -1.629 & $<0.01$ \\
\hline Baseline NfH (per doubling) & -0.113 & -1.267 to 1.011 & $>0.05$ \\
\hline \multicolumn{4}{|c|}{ Relationship with change in 9 HPT $(1,000 / s$ per year) } \\
\hline \multicolumn{4}{|l|}{ Predictor variable } \\
\hline Baseline NfL (per doubling) & -0.046 & -0.904 to 0.858 & $>0.05$ \\
\hline Baseline NfH (per doubling) & -0.168 & -0.524 to 0.162 & $>0.05$ \\
\hline \multicolumn{4}{|c|}{$\begin{array}{l}\text { Abbreviations: } 9 \mathrm{HPT}=9 \text {-hole peg test; } 25 \mathrm{FW}=\text { timed } 25 \text {-foot walk; EDSS = Expanded Disability Status Scale; } \mathrm{NfH}=\text { neurofilament heavy; NfL = neurofilament } \\
\text { light. } \\
\text { The results of } 6 \text { separate models are presented, with EDSS, } 25 \mathrm{FW} \text {, or } 9 \mathrm{HPT} \text { as the dependent variables and NfL or NfH data as the predictor variables. EDSS } \\
\text { score is reported as the score; both } 9 \mathrm{HPT} \text { and } 25 \mathrm{FW} \text { are reported as a speed }\left(9 \mathrm{HPT} \text { as } 1,000 \times \mathrm{s}^{-1} \text { and } 25 \mathrm{FW} \text { as } \mathrm{s}^{-1}\right) \text {. In all analyses, neurofilament data were log } 2 \\
\text { transformed. Results are from covariate-adjusted models as indicated in the Methods section. } p \text { Value bounds }(</>0.05 \text { and }<>>0.01) \text { can only be inferred from } \\
\text { the } 95 \% \text { and } 99 \% \text { bias-corrected and accelerated cluster bootstrap }(10,000 \text { replications) Cls. }\end{array}$} \\
\hline
\end{tabular}

changes in serum NfL. We speculate that the latter may be due to the association between neuroinflammation and NfL persisting independent of such neuroprotective treatment. Future work should focus on replicating this NfL analysis in samples from the ongoing phase 3 MS-STAT2 clinical trial, once the effects of simvastatin on clinical disability progression are confirmed, and also on developing novel CNS biomarkers capable of capturing neuroprotective treatment effects independent of neuroinflammation.
In 2 studies assessing the neuroprotective potential of sodium channel blockade (with phenytoin in acute optic neuritis and lamotrigine in SPMS), $\mathrm{NfH}$ has shown promise as a biomarker of neuroprotective treatment. ${ }^{11,12}$ Our data, however, found no evidence of a simvastatin treatment effect on $\mathrm{NfH}$ or any associations of $\mathrm{NfH}$ with MRI or clinical measures of disease severity. Although previous studies have shown strong and consistent correlations between serum and CSF NfL, ${ }^{35}$ inconsistent results have been found for correlation between 
serum and CSF NfH. ${ }^{36-38}$ This suggests that $\mathrm{NfH}$ instability between CSF and serum compartments may have limited its potential as a biomarker in our cohort. The Quanterix Simoa NF-Light Advantage assay has been widely used and validated against clinical and MRI outcomes. The Simoa pNF-heavy Discovery assay, however, has been less widely used. One study has used this assay to demonstrate modest associations between serum $\mathrm{NfH}$ and $\mathrm{T} 2 \mathrm{LV}$ in a mixed MS cohort. $^{38}$ Although Simoa digital ELISA platforms tend to improve sensitivity and accuracy over traditional ELISA techniques, the limited data from this $\mathrm{NfH}$ assay therefore suggest that the $\mathrm{NfH}$ data should be interpreted with caution.

In conclusion, our results show that despite simvastatin treatment being associated with a significant reduction in whole brain atrophy and benefits in secondary outcomes, our results are most compatible with no important effect on serum NfL or $\mathrm{NfH}$ in SPMS. Although higher NfL is associated with greater disease severity and faster progression, our results, together with those from ibudilast, suggest that candidate nonimmunomodulatory neuroprotective treatments in PMS may act via mechanisms independent of the main determinants of serum neurofilament concentrations. While confirmation of the neuroprotective efficacy of simvastatin in SPMS is awaited from the ongoing phase 3 study, our results, together with those of others, suggest that the utility of serum neurofilaments as biomarkers of treatment response in progressive MS may be limited to interventions that are either known to suppress acute or chronic neuroinflammatory activity or to otherwise directly affect neuroaxonal injury.

\section{Study Funding}

No targeted funding reported.

\section{Disclosure}

T.E. Williams has received honorarium for educational talks from Novartis and Merck. K.P. Holdsworth, J.M. Nicholas, A. Eshaghi, T. Katsanouli, H. Wellington, and A. Heslegrave report no disclosures relevant to the manuscript. H. Zetterberg has served at scientific advisory boards for Denali, Roche Diagnostics, Wave, Samumed, Siemens Healthineers, Pinteon Therapeutics, Nervgen, AZTherapies, and CogRx; has given lectures in symposia sponsored by Cellectricon, Fujirebio, Alzecure, and Biogen; and is a cofounder of Brain Biomarker Solutions in Gothenburg AB (BBS), which is a part of the GU Ventures Incubator Program. C. Frost reports no disclosures. J. Chataway has received support from the Efficacy and Mechanism Evaluation Programme and Health Technology Assessment Programme (NIHR); UK Multiple Sclerosis Society; the National Multiple Sclerosis Society; and the Rosetrees Trust. He is supported in part by the National Institute for Health Research, University College London Hospitals, Biomedical Research Centre, London, UK. He has been a local principal investigator for a trial in MS funded by the Canadian MS society; a local principal investigator for commercial trials funded by: Actelion, Biogen, Novartis and Roche; has received an investigator grant from Novartis; and has taken part in advisory boards/consultancy for Azadyne,
Biogen, Celgene, Janssen, MedDay, Merck, NervGen, Novartis and Roche. Go to Neurology.org/NN for full disclosures.

\section{Publication History}

Received by Neurology: Neuroimmunology \& Neuroinflammation June 16, 2021. Accepted in final form November 23, 2021.

Appendix Authors

\begin{tabular}{|c|c|c|}
\hline Name & Location & Contribution \\
\hline $\begin{array}{l}\text { Thomas E. } \\
\text { Williams, BA, } \\
\text { MB BChir, } \\
\text { MRCP }\end{array}$ & $\begin{array}{l}\text { Queen Square Multiple } \\
\text { Sclerosis Centre, UCL } \\
\text { Queen Square Institute of } \\
\text { Neurology, United } \\
\text { Kingdom }\end{array}$ & $\begin{array}{l}\text { Acquisition of patient } \\
\text { samples, neurofilament } \\
\text { laboratory analysis, data } \\
\text { analysis and interpretation, } \\
\text { and drafting of the } \\
\text { manuscript and revisions }\end{array}$ \\
\hline $\begin{array}{l}\text { Katherine P. } \\
\text { Holdsworth, } \\
\text { MSc }\end{array}$ & $\begin{array}{l}\text { London School of Hygiene } \\
\text { and Tropical Medicine, } \\
\text { United Kingdom }\end{array}$ & $\begin{array}{l}\text { Data analysis and } \\
\text { interpretation and } \\
\text { manuscript revisions }\end{array}$ \\
\hline $\begin{array}{l}\text { Jennifer M. } \\
\text { Nicholas, PhD }\end{array}$ & $\begin{array}{l}\text { London School of Hygiene } \\
\text { and Tropical Medicine, } \\
\text { United Kingdom }\end{array}$ & $\begin{array}{l}\text { Data analysis and } \\
\text { interpretation and } \\
\text { manuscript revisions }\end{array}$ \\
\hline $\begin{array}{l}\text { Arman } \\
\text { Eshaghi, PhD }\end{array}$ & $\begin{array}{l}\text { Queen Square Multiple } \\
\text { Sclerosis Centre, UCL } \\
\text { Queen Square Institute of } \\
\text { Neurology, United } \\
\text { Kingdom }\end{array}$ & $\begin{array}{l}\text { MRI analysis and } \\
\text { manuscript revisions }\end{array}$ \\
\hline $\begin{array}{l}\text { Theodora } \\
\text { Katsanouli, } \\
\text { MSc }\end{array}$ & $\begin{array}{l}\text { London School of Hygiene } \\
\text { and Tropical Medicine, } \\
\text { United Kingdom }\end{array}$ & $\begin{array}{l}\text { Data analysis and } \\
\text { interpretation and } \\
\text { manuscript revisions }\end{array}$ \\
\hline $\begin{array}{l}\text { Henrietta } \\
\text { Wellington, } \\
\text { PhD, FRCP }\end{array}$ & $\begin{array}{l}\text { UK Dementia Research } \\
\text { Institute at UCL }\end{array}$ & $\begin{array}{l}\text { Supervision of } \\
\text { neurofilament laboratory } \\
\text { analysis and manuscript } \\
\text { revisions }\end{array}$ \\
\hline $\begin{array}{l}\text { Amanda } \\
\text { Heslegrave, } \\
\text { PhD }\end{array}$ & $\begin{array}{l}\text { UK Dementia Research } \\
\text { Institute at UCL }\end{array}$ & $\begin{array}{l}\text { Supervision of } \\
\text { neurofilament laboratory } \\
\text { analysis and manuscript } \\
\text { revisions }\end{array}$ \\
\hline $\begin{array}{l}\text { Henrik } \\
\text { Zetterberg, } \\
\text { PhD }\end{array}$ & $\begin{array}{l}\text { UK Dementia Research } \\
\text { Institute at UCL }\end{array}$ & $\begin{array}{l}\text { Oversight of neurofilament } \\
\text { laboratory analysis, data } \\
\text { analysis and interpretation, } \\
\text { and manuscript revisions }\end{array}$ \\
\hline $\begin{array}{l}\text { Chris Frost, } \\
\text { PhD }\end{array}$ & $\begin{array}{l}\text { London School of Hygiene } \\
\text { and Tropical Medicine, } \\
\text { United Kingdom }\end{array}$ & $\begin{array}{l}\text { Supervision of data analysis } \\
\text { and interpretation and } \\
\text { manuscript revisions }\end{array}$ \\
\hline $\begin{array}{l}\text { Jeremy } \\
\text { Chataway, } \\
\text { PhD, FRCP }\end{array}$ & $\begin{array}{l}\text { Queen Square Multiple } \\
\text { Sclerosis Centre, UCL } \\
\text { Queen Square Institute of } \\
\text { Neurology, United } \\
\text { Kingdom }\end{array}$ & $\begin{array}{l}\text { Chief investigator of the MS- } \\
\text { STAT clinical trial, study } \\
\text { design and conception, data } \\
\text { interpretation, and } \\
\text { manuscript revisions }\end{array}$ \\
\hline
\end{tabular}

\section{References}

1. Lublin FD, Reingold SC, Cohen JA, et al. Defining the clinical course of multiple sclerosis. Neurology. 2014;83(3):278-286.

2. Chataway J, Schuerer N, Alsanousi A, et al. Effect of high-dose simvastatin on brain atrophy and disability in secondary progressive multiple sclerosis (MS STAT): a randomised, placebo-controlled, phase 2 trial. Lancet. 2014 383(9936):2213-2221.

3. Chan D, Binks S, Nicholas JM, et al. Effect of high-dose simvastatin on cognitive, neuropsychiatric, and health-related quality-of-life measures in secondary progressive multiple sclerosis: secondary analyses from the MS-STAT randomised, placebocontrolled trial. Lancet Neurol. 2017;16(8):591-600. 
4. Sormani MP, Haering DA, Kropshofer H, et al. Blood neurofilament light as a potential endpoint in Phase 2 studies in MS. Ann Clin Transl Neurol. 2019;6(6) 1081-1089.

5. Williams T, Zetterberg $\mathrm{H}$, Chataway J. Neurofilaments in progressive multiple sclerosis: a systematic review. J Neurol. 2021;268(9):3212-3222.

6. Bar-Or A, Thanei GA, Harp CT, et al. Blood neurofilament light levels are lowered to a healthy donor range in patients with RMS and PPMS following ocrelizumab treatment. Presented at the 35th Congress of ECTRIMS; 2019; Stockholm.

7. Kapoor R, Sellebjerg F, Hartung HP, et al. Natalizumab reduced serum levels of neurofilament light chain in secondary progressive multiple sclerosis patients from the phase 3 ASCEND study. Presented at the 34th Congress of ECTRIMS; 2018; Berlin.

8. Kuhle J, Kropshofer H, Haering D, et al. Neurofilament light levels in the blood of patients with secondary progressive MS are higher than in primary progressive MS and may predict brain atrophy in both MS subtypes. Presented at the 34th Congress of ECTRIMS; 2018; Berlin.

9. Fox R, Raska P, Barro C, et al. Neurofilament light chain in a phase 2 clinical trial of ibudilast in progressive multiple sclerosis. Mult Scler. 2021;27(13):2014-2022.

10. Kapoor R, Smith KE, Allegretta M, et al. Serum neurofilament light as a biomarker in progressive multiple sclerosis. Neurology. 2020;95(10):436-444.

11. Gnanapavan S, Grant D, Morant S, et al. Biomarker report from the phase II lamotrigine trial in secondary progressive MS - neurofilament as a surrogate of disease progression. PLoS One. 2013;8(8):e70019.

12. Raftopoulos R, Kuhle J, Grant D, et al. Neurofilament results for the phase II neuroprotection study of phenytoin in optic neuritis. Eur J Neurol. 2021;28(2): 587-594.

13. Quanterix. Simoa NF-light Advantage Kit HD-1/HD-X data sheet. Epub 2017:1-2.

14. Quanterix. Simoa pNF-heavy Discovery Kit HD-1/HD-X data sheet. 2017:1-2.

15. Eshaghi A, Kievit RA, Prados F, et al. Applying causal models to explore the mechanism of action of simvastatin in progressive multiple sclerosis. Proc Natl Acad Sci USA. 2019;116(22):11020-11027.

16. Liu G, Lu K, Mogg R, Mallick M, Mehrotra D. Should baseline be a covariate or dependent variable in analyses of change from baseline in clinical trials? Stat Med. 2009;28(20):2509-2530

17. European Medicines Agency. Statistical principles for clinical trials. Eur Med Agency. 1998;5(7):29.

18. Matthews J, Altman D, Campbell M, Royston P. Analysis of serial measurements in medical research. Br Med J. 1990;300(6725):230-235.

19. Frost C, Kenward MG, Fox NC. The analysis of repeated "direct" measures of change illustrated with an application in longitudinal imaging. Stat Med. 2004;23(21): 3275-3286.

20. Barkhof F, Simon JH, Fazekas F, et al. MRI monitoring of immunomodulation in relapse-onset multiple sclerosis trials. Nat Rev Neurol. 2012;8(1):13-21.
21. World Medical Association. Declaration of Helsinki: ethical principles for medical research involving human subjects. 2013. Accessed January 2021. wma.net/en/30publications/10policies/b3/17c.pdf.

22. Maggi $\mathrm{P}$, Kuhle J, Schädelin $\mathrm{S}$, et al. Chronic white matter inflammation and serum neurofilament levels in multiple sclerosis. Neurology. 2021;97(6):e543-e553.

23. Ontaneda D, Thompson AJ, Fox RJ, Cohen JA. Progressive multiple sclerosis: prospects for disease therapy, repair, and restoration of function. Lancet. 2017, 389(10076):1357-1366.

24. Palladino R, Marrie RA, Majeed A, Chataway J. Evaluating the risk of macrovascular events and mortality among people with multiple sclerosis in England. JAMA Neurol. 2020;77(7):820-828.

25. Marrie RA, Rudick R, Horwitz R, et al. Vascular comorbidity is associated with more rapid disability progression in multiple sclerosis. Neurology. 2010;74(13):1041-1047.

26. Jakimovski D, Gandhi S, Paunkoski I, et al. Hypertension and heart disease are associated with development of brain atrophy in multiple sclerosis: a 5-year longitudinal study. Eur J Neurol. 2019;26(1):87-e8.

27. Sormani MP, Arnold DL, De Stefano N. Treatment effect on brain atrophy correlates with treatment effect on disability in multiple sclerosis. Ann Neurol. 2014;75(1):43-49.

28. Sastre-Garriga J, Pareto D, Battaglini M, et al. MAGNIMS consensus recommendations on the use of brain and spinal cord atrophy measures in clinical practice. Nat Rev Neurol. 2020;16(3):171-182.

29. Cifelli A, Arridge M, Jezzard P, Esiri MM, Palace J, Matthews PM. Thalamic neurodegeneration in multiple sclerosis. Ann Neurol. 2002;52(5):650-653.

30. Popescu V, Klaver R, Voorn P, et al. What drives MRI-measured cortical atrophy in multiple sclerosis? Mult Scler. 2015;21(10):1280-1290.

31. Fox RJ, Coffey CS, Conwit R, et al. Phase 2 trial of ibudilast in progressive multiple sclerosis. N Engl J Med. 2018;379(9):846-855.

32. Barkhof F, Hulst HE, Drulović J, Uitdehaag BMJ, Matsuda K, Landin R. Ibudilast in relapsingremitting multiple sclerosis: a neuroprotectant? Neurology. 2010;74(13):1033-1040.

33. Bridel C, Van Wieringen WN, Zetterberg H, et al. Diagnostic value of cerebrospinal fluid neurofilament light protein in neurology: a systematic review and meta-analysis. JAMA Neurol. 2019;76(9):1035-1048.

34. Olsson B, Alberg L, Cullen NC, et al. NFL is a marker of treatment response in children with SMA treated with nusinersen. J Neurol. 2019;266(9):2129-2136.

35. Novakova L, Zetterberg H, Sundstrom $\mathrm{P}$, et al. Monitoring disease activity in multiple sclerosis using serum neurofilament light protein. Neurology. 2017;89(22):2230-2237.

36. Vorobyeva A, Fominykh V, Zakharova M. Biochemical markers of neurodegeneration in multiple sclerosis. Mult Scler. 2013;19(11):369.

37. Eikelenboom MJ, Uitdehaag BMJ, Petzold A. Blood and CSF biomarker dynamics in multiple sclerosis: implications for data interpretation. Mult Scler Int. 2011;2011:1-6.

38. Verberk I, Koel-Simmelink M, Twaalfhoven $\mathrm{H}$, et al. Ultrasensitive immunoassay allows measurement of serumneurofilament heavy in multiple sclerosis. Mult Scler Relat Disord. 2021;50:102840. 


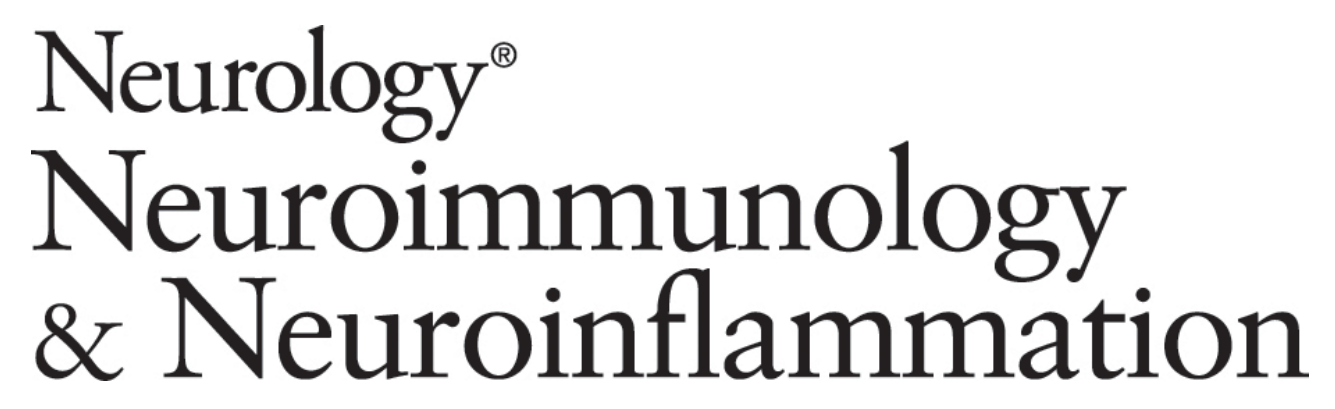
Assessing Neurofilaments as Biomarkers of Neuroprotection in Progressive Multiple Sclerosis: From the MS-STAT Randomized Controlled Trial
Thomas E. Williams, Katherine P. Holdsworth, Jennifer M. Nicholas, et al.
Neurol Neuroimmunol Neuroinflamm 2022;9;
DOI 10.1212/NXI.0000000000001130

This information is current as of January 14, 2022

Neurol Neuroimmunol Neuroinflamm is an official journal of the American Academy of Neurology.

Published since April 2014, it is an open-access, online-only, continuous publication journal. Copyright

Copyright $\odot 2022$ The Author(s). Published by Wolters Kluwer Health, Inc. on behalf of the American

Academy of Neurology.. All rights reserved. Online ISSN: 2332-7812.

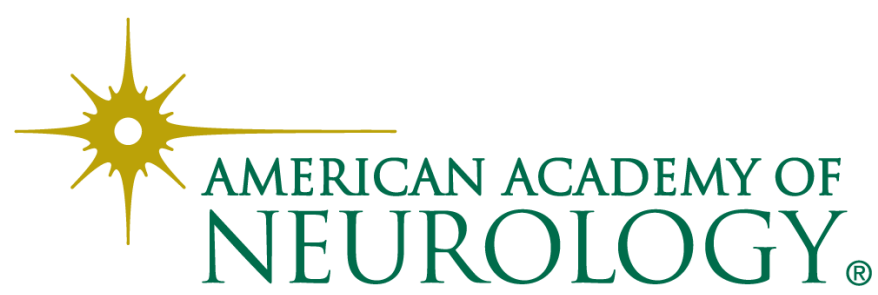




\section{Updated Information \& Services}

References

Citations

Subspecialty Collections

Permissions \& Licensing

Reprints including high resolution figures, can be found at: http://nn.neurology.org/content/9/2/e1130.full.html

This article cites 32 articles, 2 of which you can access for free at: http://nn.neurology.org/content/9/2/e1130.full.html\#\#ref-list-1

This article has been cited by 1 HighWire-hosted articles: http://nn.neurology.org/content/9/2/e1130.full.html\#\#otherarticles

This article, along with others on similar topics, appears in the following collection(s):

\section{Class I}

http://nn.neurology.org//cgi/collection/class_1

Clinical trials Randomized controlled (CŌNSORT agreement)

http://nn.neurology.org//cgi/collection/clinical_trials_randomized_cont rolled_consort_agreement

Multiple sclerosis

http://nn.neurology.org//cgi/collection/multiple_sclerosis

Information about reproducing this article in parts (figures,tables) or in its entirety can be found online at:

http://nn.neurology.org/misc/about.xhtml\#permissions

Information about ordering reprints can be found online: http://nn.neurology.org/misc/addir.xhtml\#reprintsus

Neurol Neuroimmunol Neuroinflamm is an official journal of the American Academy of Neurology.

Published since April 2014, it is an open-access, online-only, continuous publication journal. Copyright

Copyright $\odot 2022$ The Author(s). Published by Wolters Kluwer Health, Inc. on behalf of the American Academy of Neurology.. All rights reserved. Online ISSN: 2332-7812.

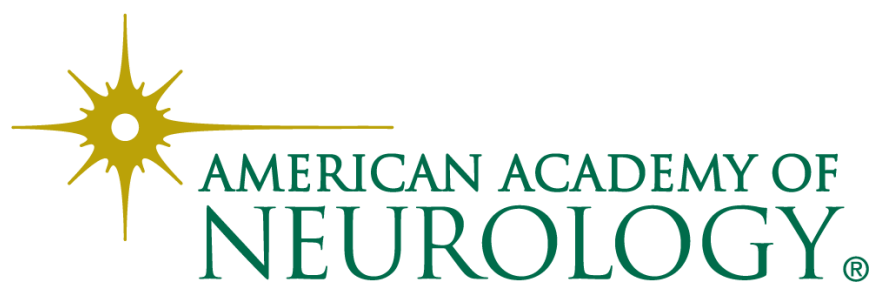

